\title{
Pathways to care for people with mental health problems coming to a tertiary care hospital in Islamabad
}

Khan FR ${ }^{1}$, Mazhar $\mathrm{M}^{1}$, Ali $\mathrm{M}^{2}$, Bashir $\mathrm{F}^{3}$

\section{1,2 Department of Psychiatry, Al Nafees Medical College and Hospital, Isra University, Islamabad Campus, Pakistan}

Email: mazhar.mahpara@gmail.com

\section{OBJECTIVE}

To identify pathways to care for people with mental health problems coming to psychiatry department of a tertiary care hospital

\section{METHODOLOGY}

-This descriptive cross sectional study was conducted on all new patients attending the psychiatry Out-patient and Inpatient facilities of Al Nafees Medical Hospital for 16 months.

- Patients were administered a questionnaire after obtaining their informed consent. It consisted of questions regarding subject's demographics, pathways to care and modes of treatment.

Table showing frequency of various pathways to care for people with mental health problems $(\mathrm{N}=231)$

\begin{tabular}{|c|c|}
\hline Pathways to care & Frequency(Percentage) \\
\hline Faith healer & $104(44.8 \%)$ \\
\hline Homeopathic care & $30(12.9 \%)$ \\
\hline Ayurvedic & $6(2.6 \%)$ \\
\hline Hakimi & $19(8.2 \%)$ \\
\hline $\begin{array}{l}\text { Allopathic treatment from a } \\
\text { non-specialist }\end{array}$ & $60(25.9 \%)$ \\
\hline $\begin{array}{l}\text { Allopathic treatment from } \\
\text { specialist doctor other than } \\
\text { psychiatrist }\end{array}$ & $58(25 \%)$ \\
\hline Others & $1(0.4 \%)$ \\
\hline No Intervention & $65(28 \%)$ \\
\hline
\end{tabular}

\section{RESULTS}

-Among 231 patients more than a quarter of patients, $44.8 \%$ had been to faith healers and many had received traditional forms of treatment like homeopathic 12.9\%, Ayurvedic $2.6 \%$ and Hakeemi 8.2\%.

- Half of patients had seen a general physician or a non psychiatric specialist, $51 \%$.

-Around $28 \%$ of patients had come directly for a first visit to a psychiatrist.

-Damdarood 45\% and Taweez 30.7\% comprised major forms of interventions.

-38\% of patients were prescribed non psychotropic drugs and $29 \%$ were put on sedatives/hypnotics.

\section{CONCLUSION}

-People with mental health illness visit multiple health care providers before reporting to a mental health specialist.

- Majority of patients coming for psychiatric treatment first report to traditional healers or general physicians.

-This study signifies the need to design an organic and collaborative system of mental health care.

\section{REFERENCES}

-Burns JK, Tomita A. Traditional and religious healers in the pathway to care for people with mental disorders in Africa: a systematic review and meta-analysis. Soc Psychiatry Psychiatr Epidemiol. 2015;50(6):867-77.

-Naqvi HA, Hussain S, Zaman M, Islam M. Pathways to Care: Duration of Untreated Psychosis from Karachi, Pakistan. PLoS One 2009, $4(10): 7409$.

-Giasuddin NA, Chowdhury NF, Hashimoto N, Fujisawa D, Waheed S. Pathways to psychiatric care in Bangladesh. Soc Psychiatry Psychiatr Epidemiol. 2012;47:129-36.

-Volpe U, Mihai A, Jordanova V, Sartorius N. The pathways to mental healthcare worldwide: a systematic review. Curr Opin Psychiatry. 2015;28(4):299-306. 